\title{
INFLUÊ NCIA DA MINERALOGIA DA FRAÇÃO ARGILA NAS PROPRIEDADES FÍSICAS DE LATOSSOLOS DA REGIÃO SUDESTE DO BRASIL ${ }^{(1)}$
}

\author{
M. M. FERREIRA(2) B. FERNANDES ${ }^{(3)} \&$ N. CURI (2)
}

\begin{abstract}
RESUMO
Visando avaliar a influência da mineralogia da fração argila nas propriedades físicas de Latossolos do sudeste brasileiro, selecionaram-se sete Latossolos, representativos deste grupamento, ocorrentes nos estados de Minas Gerais e Espírito Santo, apresentando distintas feições morfológicas associadas à estrutura do solo. A amostragem dos solos foi efetuada no horizonte B latossólico, sendo retiradas amostras deformadas e indeformadas. No laboratório, foram efetuadas análises químicas, físicas e mineralógicas. Estudos de regressão e correlação levados a efeito com os resultados das diversas caracterizações mostraram que as propriedades físicas associadas à estrutura foram marcadamente influenciadas pela composição mineralógica da fração argila dos Latossolos. O efeito do Al sobre as propriedades físicas estudadas foi mais pronunciado do que o do $\mathrm{Fe}$. Latossolos cauliníticos apresentaram maior densidade do solo, menor estabilidade de agregados em água, menor macroporosidade e menor permeabilidade quando comparados com Latossolos gibbsíticos. A permeabilidade dos Latossolos estudados aumentou com o teor de argila.
\end{abstract}

Termos de indexação: densidade do solo, estabilidade de agregados, porosidade do solo, infiltração de água.

\footnotetext{
(1) Parte da Tese de Doutorado apresentada pelo primeiro autor ao Curso de Pós-Graduação em Sol os e Nutrição de Plantas, U niversidade Federal deViçosa - UFV. Trabalho apresentado noXXII Congresso Brasileiro de Ciência do Solo, Recife (PE), 23-31 de julho de 1989. Recebido para publicação em abril de 1998 e aprovado em janeiro de 1999.

(2) Professor do Departamento de Ciência do Solo da Universidade Federal de Lavras, CEP 37200-000 Lavras (MG). Bolsista do CNPq.

(3) In memoriam.
} 


\title{
SUMMARY: INFLUENCE OF THE CLAY FRACTION MINERALOGY ON THE PHYSICAL PROPERTIES OF LATOSOLS (OXISOLS) FROM SOUTHEASTERN BRAZIL
}

\begin{abstract}
Aiming to evaluatetheinfluence of theday fraction mineral ogy on thephysical properties of Latosols (Oxisols) from southeastern Brazil, seven Latosols, representative of this group, were selected from the states of Minas Gerais and Espírito Santo, having distinct morphol ogical features associated with soil structure. Thesampl ing of soils was performed in thelatossolicB horizon, with disturbed and undisturbed samples being collected. Chemical, physical and mineralogical characterizations wereperformed in thelaboratory. Regression and correlation analyses taking into account the results of the various characterizations showed that the physical properties associated with soil structure are markedly influenced by themineralogical composition of the day fraction of $L$ atosols. TheAl effect on thephysical properties was more pronounced than the Fe effect. Kaolinitic L atosols present higher bulk density, lower water aggregate stability, smaller macroporosity and permeability values when compared to gibbsitic Latosols. The permeability of the studied Latosols increases with the clay content.
\end{abstract}

Index terms: bulk density, aggregates stability, soil porosity, water infiltration.

\section{INTRODUÇÃO}

A estrutura do solo é considerada como uma de suas mais importantes propriedades do ponto de vista agrícola. A ela estão relacionadas outras propriedades fundamentais nas relações sol o-planta. De acordo com Marcos (1968), o estudo da estruturação do solo no sentido morfológico é puramente descritivo, enquanto, do ponto de vista físico, é funcional. Segundo o autor, embora os agregados sejam separados, sua estabilidade avaliada e sua formação extensamenteestudada, não há conhecimento de alguma lei ou princípio comandando a sua formação, tamanho ecomposição. Tentativa nesta direção foi reportada, entre outros, no trabalho de Harris et al. (1966). Nesse estudo, discutiu-se amplamente a atuação de diversos agentes que controlam a formação, estabilização e degradação de agregados no solo, tendo esses autores apontado Lutz, ainda em 1936, como responsável por um dos primeiros registros da participação dos óxidos de Fe na agregação de sol os lateríticos.

Tem-se verificado significativa intensificação nos estudos desta natureza envolvendo óxidos de Fe e de Al, notadamente a partir dos trabalhos de Mcl ntyre (1956), Mehra \& J ackson (1960), N orrish \& Taylor (1961), Resende (1976), entre outros.

Estudos anteriores desenvol vidos por Deshpande et al. (1968) revelaram que os óxidos de Fe desempenhavam papel de importância secundária na agregação de solos de clima tropical. Por sua vez, Pinheiro-Dick \& Schwertmann (1996) e Lima \& Anderson (1997) demonstraram a participação efetiva dos óxidos de Fe na agregação de Oxissolos. Mais recentemente, Muggler (1998) comprovou que o modo de formação e a mineralogia dos compostos de Fe determinam seu eventual efeito na agregação desses solos. Quanto aos óxidos de Al, o predomínio de gibbsita na fração argila de Latossolos favorece maior agregação (Silva et al., 1998), conseqüência da manutenção da estrutura microgranular nesses solos, resultando em elevados valores de permeabilidade (Resende et al., 1998).

Conforme Deshpande et al. (1968), os óxidos de Fe ocorrem predominantemente como partículas discretas, as quais seriam ineficientes como agentes cimentantes. Posteriormente, Schwertmann \& Kämpf (1985), estudando as propriedades desses óxidos (goethita e hematita) em solos cauliníticos do Brasil Central e da região Sul, observaram que esses se agregam mutuamente, ao invés de recobrirem a estrutura da caulinita. Do mesmo modo que Deshpande et al. (1968), também Schwertmann \& Kämpf (1985) não concordam com a opinião amplamente difundida de que o revestimento da caulinita pela hematita e goethita seja a causa para a forte agregação encontrada nos solos tropicais e subtropicais. Mais recentemente, Pinheiro-Dick \& Schwertmann (1996) relataram que, em Oxissolos, hematita e goethita formam microagregados homogêneos com gibbsita, caulinita e quartzo.

Diante desta exposição, verifica-se que, embora o volume de informações a respeito desses componentes nos dias atuais seja expressivo, não existe uma teoria única sobre seus efeitos na estabilização da estrutura do solo. Assim, busca-se no presente estudo avaliar a participação dos constituintes mineralógicos da fração argila no comportamento de propriedades físicas de L atossolos ocorrentes na região Sudeste do Brasil. 


\section{MATE RIAL E MÉTODOS}

Utilizaram-se amostras deformadas e indeformadas da porçãosuperior do horizonteBw desete Latossol os de Minas Gerais e Espírito Santo, relacionados no quadro 1. A seleção desses solos se efetuou, preliminarmente, fazendo-se consultas aos boletins do Serviço Nacional de Levantamento e Conservação doSolos - EMBRAPA (EMBRAPA, 1978; 1980).

As diversas amostras foram submetidas a análises químicas, físicas e mineralógicas. Algumas informações relativas a tais caracterizações, que não foram levadas em consideração no presente estudo, podem ser encontradas em Ferreira (1988).

$\mathrm{Na}$ caracterização química dos solos, foram determinadas as formas de Fe e Al extraídos na TFSA pelo ataque sulfúrico, segundo Vettori (1969) e EMBRAPA (1979). Ferro $\left(\mathrm{Fe}_{\mathbf{d}}\right)$ e alumínio $\left(\mathrm{Al}_{\mathrm{d}}\right)$ foram determinados na fração argila, com solução de ditionito-citrato-bicarbonato de sódio (DCB), de acordo com Mehra \& J ackson (1960). As formas de ferro $\left(\mathrm{Fe}_{0}\right)$ e alumínio $\left(\mathrm{Al}_{\mathrm{o}}\right)$ de baixa cristalinidade foram determinadas, também na fração argila, com solução de oxalato de amônio ácido, conforme Schwertmann (1964).

$\mathrm{Na}$ caracterização mineralógica, caulinita e gibbsita foram quantificadas, na fração argila desferrificada, por meio de análise térmica diferencial. Goethita e hematita foram determinadas, na fração argila concentrada com $\mathrm{NaOH} 5 \mathrm{~mol} \mathrm{L-1}$, de acordo com Kämpf \& Schwertmann (1982) e Resende et al. (1987), com base em difratogramas obtidos em aparel ho de raios-X munido com tubo de cobre, pelo método do pó.
$\mathrm{Na}$ caracterização física dos solos, foram utilizadas amostras deformadas e indeformadas, estas últimas coletadas em tubos de PVC, empregando-se método semel hante ao descrito por Mielke(1973).

$\mathrm{Na}$ análise granulométrica, a dispersão foi efetuada mecânica (agitação rápida) equimicamente $\left(\mathrm{NaOH} 0,5 \mathrm{~mol} \mathrm{~L}^{-1}\right)$, ao passo que, na determinação da argila dispersa em água, utilizaram-sea dispersão mecânica ea água destilada. E mpregou-se o método da pipeta (Day, 1965) para as determinações desilte e argila e tamisagem para a areia. O índice de floculação foi calculado por meio da expressão: I.F . $\%=[($ Argila Total - Argila Dispersa em Água $) /$ Argila Total ] x 100.

A densidade do solo foi determinada em amostras indeformadas, dividindo-se o peso seco em estufa (105-110C) do material contido no tubo de PVC pelo seu respectivo volume.

A estabilidade de agregados foi avaliada por peneiramento úmido e seco. As amostras para essa determinação consistiram de blocos de solo com estrutura natural. Uma vez secos ao ar, os blocos foram peneirados manual mente em peneiras de malhas de 9,52 e 4,76 mm. Foram empregados nas análises aqueles agregados retidos na peneira de $4,76 \mathrm{~mm}$. Na análise da estabilidade pelo peneiramento úmido, os agregados foram submetidos ao préumedecimento lento por meio de atomização com água destilada. Duas horas após permanecerem em dessecador com atmosfera saturada, os agregados foram agitados, durante $15 \mathrm{~min}$, em jogo de peneiras com mal has de 2,0; 1,0; 0,5 e 0,105 mm, dentro de recipiente que continha água, conforme proposição

\section{Quadro 1. Classificação, cor, estrutura, unidades litológicas e localização dos Latossolos estudados}

\begin{tabular}{|c|c|c|c|c|c|}
\hline Ordem & Classificação & Cor úmida & Macroestrutura & $\begin{array}{l}\text { Unidade } \\
\text { litoestratigráfica }\end{array}$ & Localização \\
\hline 1 & $\begin{array}{l}\text { Latossolo Vermel ho-Escuro distrófico (LEd) } \\
\text { textura muito argil osa }\end{array}$ & $2,5 Y R \quad 4 / 6$ & $\begin{array}{l}\text { Muito pequena, } \\
\text { blocos subangulares }\end{array}$ & Grupo Canastra & Sacramento (MG) \\
\hline 2 & $\begin{array}{l}\text { Latossolo Roxo distrófico (LRd) } \\
\text { textura argilosa }\end{array}$ & $10,0 \mathrm{R} 3 / 4$ & $\begin{array}{l}\text { Muito pequena, } \\
\text { granular }\end{array}$ & $\begin{array}{l}\text { Formação Mata } \\
\text { da Corda }\end{array}$ & Patos de Minas (MG) \\
\hline 3 & $\begin{array}{l}\text { Latossolo Vermelho-Escuro distrófico (LEd) } \\
\text { textura argil osa }\end{array}$ & $2,5 Y R 3 / 6$ & $\begin{array}{l}\text { Muito pequena, } \\
\text { granular }\end{array}$ & Grupo Bambuí & Rio Paranaíba (MG) \\
\hline 4 & $\begin{array}{l}\text { Latossolo Vermel ho-Amarelo distrófico (LVd) } \\
\text { textura argil osa }\end{array}$ & $2,5 Y 6 / 4$ & $\begin{array}{l}\text { Pequena, blocos } \\
\text { subangulares }\end{array}$ & $\begin{array}{l}\text { Formação } \\
\text { Urucuia }\end{array}$ & São Gotardo (MG) \\
\hline 5 & $\begin{array}{l}\text { Latossolo Amarelo álico (LAa) } \\
\text { textura argilosa }\end{array}$ & $10,0 Y R 5 / 6$ & $\begin{array}{l}\text { Pequena, blocos } \\
\text { subangulares }\end{array}$ & Grupo Barreiras & Marataízes (ES) \\
\hline 6 & $\begin{array}{l}\text { Latossolo Vermel ho-Escuro distrófico (LEd) } \\
\text { textura muito argil osa }\end{array}$ & $10,0 \mathrm{R} 3 / 6$ & $\begin{array}{l}\text { Muito pequena, } \\
\text { granular }\end{array}$ & $\begin{array}{l}\text { Complexo } \\
\text { Granito-Gnaisse }\end{array}$ & Lavras (MG) \\
\hline 7 & $\begin{array}{l}\text { Latossolo Una distrófico (LUd) } \\
\text { textura muito argilosa }\end{array}$ & $5,0 Y R 4 / 6$ & $\begin{array}{l}\text { Pequena, blocos } \\
\text { subangulares }\end{array}$ & $\begin{array}{l}\text { Complexo } \\
\text { Granito-Gnaisse }\end{array}$ & Viçosa (MG) \\
\hline
\end{tabular}


de Yoder (1936). Na análise da estabilidade pelo peneiramento seco, os agregados, secos ao ar, foram agitados, durante 15 min, no mesmojogo de peneiras anterior, em aparel ho de movimento vibratório. Nas duas situações, adotou-se comoíndice de estabilidade oDiâmetro Médio Geométrico (DMG), de acordo com Mazurack (1950).

Para determinar a distribuição de poros por tamanho e permeabilidade, utilizaram-se também amostras indeformadas. Na distribuição dos diâmetros dos poros, foram utilizados o modelo capilar e as colunas de água de 20,40,60 e $100 \mathrm{~cm}$. Empregou-se o método do funil (Bouma, 1973). A equação utilizada foi :

$$
\mathrm{D}=4 \gamma / \text { d.h.g }
$$

em que $\mathrm{D}=$ diâmetro dos poros em $\mathrm{cm} ; \gamma=$ tensão superficial da água em dina $\mathrm{cm}^{-1} ; \mathrm{d}=$ densidade da água em $\mathrm{g} \mathrm{cm}^{-3} ; \mathrm{h}=$ altura da coluna de água em $\mathrm{cm}, \mathrm{eg}=$ acel eração devida à gravidade em $\mathrm{cm} \mathrm{s}^{-2}$.

A condutividade hidráulica do solo saturado foi avaliada, conforme Fernandes et al. (1983), por meio de um sistema ajustável de permeâmetros com uma lâmina de água constante igual a $2 \mathrm{~cm}$. Foram tomados cuidados especiais para evitar percolação de água ao longo da parede interna do tubo. As amostras foram submeti das a um pré-umedecimento muito lento, por capilaridade, durante $24 \mathrm{~h}$ que antecederam as observações, a fim de expulsar o ar do solo contido notubo dePVC. As leituras do volume percolado foram feitas de hora em hora, durante sete horas consecutivas. Para calcular a condutividade hidráulica, utilizou-se a equação de Darcy:

$$
\mathrm{Ks}=\mathrm{Q} / \mathrm{At} . \mathrm{L} / \mathrm{H}
$$

em que $\mathrm{Ks}=$ condutividade hidráulica do solo saturado, em $\mathrm{cm} \mathrm{h}^{-1} ; \mathrm{Q}=$ vol ume de água percolada no tempo t, em cm3; $A$ =área da secção transversal do tubo, em cm2; $\mathrm{H}=$ carga hidráulica total, $\mathrm{em} \mathrm{cm}$, $\mathrm{e} \mathrm{L}=$ comprimento da coluna de solo, $\mathrm{em} \mathrm{cm}$.
Com base nos resultados das diversas caracterizações, realizaram-se análises estatísticas de regressão e correlação, utilizando-se o Sistema para Análises Estatísticas (SAEG) da Central de Processamento de Dados da UFV. Todas as determinações foram feitas com cinco repetições.

\section{RESULTADOS E DISCUSSÃO}

As formas de FeeAl extraídos pelo DCB eoxalato de amônio nos diferentes Latossolos estudados encontram-se no quadro 2. Observa-se que os diferentes sol os apresentaram contrastes acentuados em suas composições químicas, ressaltando-se as amplitudes nos teores de $\mathrm{Fe}_{2} \mathrm{O}_{3}\left(43-303 \mathrm{~g} \mathrm{~kg}^{-1}\right)$ e nos valores da relação $\mathrm{Ki}$, que variaram de 0,26 a 2,15. Valores da relação $\mathrm{Ki} \leq 0,75$ (solos 1 a 4) têm-se correlacionado com mi neral ogia gi bbsítica, enquanto valores $>0,75$ (solos 5 a 7) são indicativos de mineralogia caulinítica em Latossolos (Resende \& Santana, 1988). Neste contexto, apenas o sol o 6 fugiu da tendência. Com relação às extrações com DCB e oxal ato de amônio ácido, no caso do $\mathrm{Fe}$, os resultados seguiram a mesma tendência do ataque sulfúrico, com a solução DCB apresentando maior extração que a solução de oxalato de amônio. Com relação à mineralogia dos sol os, observa-se, no quadro 3, serem eles predominantemente gibbsíticos sesqui oxídicos, constituindo exceções os sol os 5 (LAa) e 7 (LU d), que são cauliníticos. Essa mineralogia diferencial está relacionada com a macroestrutura predominantementegranular no primeiro conjunto desolos (1,2,3,4 e 6) e essencialmente em blocos subangulares no segundo conjunto (solos 5 e 7). Nota-se, ainda no quadro 3, que a goethita foi o óxido de $\mathrm{Fe}$ predominante.

Os baixos teores de óxidos de $\mathrm{Fe}$ do ataque sulfúrico dos solos 4 e 5 estão relacionados com os arenitos da F ormação U rucuia e com os sedimentos pobres em Fe do Grupo Barreiras, respectivamente

Quadro 2. Óxidos do ataque sulfúrico, Fe e Al extraídos pelo DCB e oxalato de amônio de amostras do

\begin{tabular}{|c|c|c|c|c|c|c|c|c|c|c|c|}
\hline \multirow{2}{*}{ Solo } & \multicolumn{5}{|c|}{ Ataque pelo $\mathrm{H}_{2} \mathrm{SO}_{4}$ (densidade $=1,47$ ) } & \multirow{2}{*}{$\begin{array}{c}\mathrm{SiO}_{2} / \mathrm{Al}_{2} \mathrm{O}_{3} \\
(\mathrm{Ki})\end{array}$} & \multirow{2}{*}{$\begin{array}{c}\mathrm{SiO}_{2} / \mathrm{R}_{2} \mathrm{O}_{3} \\
(\mathrm{Kr})\end{array}$} & \multirow{2}{*}{$F \mathbf{e}_{\mathbf{d}}$} & \multirow{2}{*}{$F \mathbf{e}_{\mathbf{o}}$} & \multirow{2}{*}{$A \mathbf{I}_{\mathrm{d}}$} & \multirow{2}{*}{$\mathbf{A l}_{0}$} \\
\hline & $\mathrm{SiO}_{2}$ & $\mathrm{Al}_{2} \mathbf{O}_{3}$ & $\mathrm{Fe}_{\mathbf{2}} \mathrm{O}_{3}$ & $\mathrm{TiO}_{2}$ & $\mathbf{P}_{2} \mathbf{O}_{5}$ & & & & & & \\
\hline & \multicolumn{5}{|c|}{$\mathrm{g} \mathrm{kg}^{-1}$} & & & \multicolumn{4}{|c|}{$\mathrm{g} \mathrm{kg}^{-1}$} \\
\hline $1 \mathrm{LEd}$ & 139 & 388 & 148 & 16 & 1 & 0,60 & 0,49 & 71 & 3 & 23 & 10 \\
\hline $2 \mathrm{LRd}$ & 69 & 278 & 303 & 35 & 4 & 0,42 & 0,25 & 121 & 19 & 17 & 12 \\
\hline 3 LEd & 81 & 387 & 173 & 10 & 1 & 0,35 & 0,27 & 80 & 6 & 21 & 12 \\
\hline $4 \mathrm{LVd}$ & 51 & 323 & 46 & 32 & 1 & 0,26 & 0,24 & 15 & 2 & 7 & 14 \\
\hline $5 \mathrm{LAa}$ & 204 & 161 & 43 & 11 & 0 & 2,15 & 1,84 & 40 & 2 & 8 & 2 \\
\hline 6 LEd & 210 & 326 & 132 & 16 & 1 & 1,09 & 0,87 & 67 & 4 & 17 & 8 \\
\hline $7 \mathrm{LUd}$ & 218 & 216 & 134 & 18 & 1 & 1,71 & 1,29 & 58 & 3 & 16 & 3 \\
\hline
\end{tabular}
horizonte Bw dos Latossolos estudados 
(Quadro 1). A ampla predominância de goethita em relação à hematita (Quadro 3) e o fato de serem goethitas altamente aluminosas (dados não apresentados) ajudam a explicar as relativamente baixas taxas de $\mathrm{Fe}_{2} \mathrm{O}_{3(\mathrm{~d})} / \mathrm{Fe}_{2} \mathrm{O}_{3\left(\mathrm{H}_{2} \mathrm{SO}_{4}\right)}$ (Norrish \& Taylor, 1961; Curi \& Franzmeier, 1984) em relação àquel as obtidas por Dick \& Kämpf (1988) em outros Latossolos brasileiros.

Os resultados da caracterização física dos diferentes solos encontram-se nos quadros 4 a 6 . Observando o quadro 4, percebe-se que os Latossol os estudados apresentaram classe textural argila arenosa (5), argila (2, 3 e 4) e muito argilosa (1, 6 e 7). Os teores de silte variaram de 30 (5) a $380 \mathrm{~g} \mathrm{~kg}^{-1}$ (3) e as frações ar eia fina eareia grossa complementaram reciprocamente a distribuição das partículas minerais. A argila dispersa em água apresentou expressiva amplitude de variação entre os solos $\left(0-250 \mathrm{~g} \mathrm{~kg}^{-1}\right)$.

Com relação à densidade do solo, verifica-se que seus valores variaram de 0,91 (solo 3 - gibbsítico) a

Quadro 3. Teores de caulinita, gibbsita, goethita e hematita da fração argila do horizonte Bw dos Latossolos estudados

\begin{tabular}{lcccc}
\hline Solo & Caulinita & Gibbsita & Goethita & Hematita \\
\hline & \multicolumn{5}{c}{ g kg $^{-1}$} & \\
\cline { 2 - 5 } & & & & \\
1 LEd & 192 & 661 & 135 & 12 \\
2 LRd & 5 & 803 & 34 & 158 \\
3 LEd & 5 & 853 & 92 & 50 \\
4 LVd & 54 & 918 & 28 & 0 \\
5 LAd & 883 & 38 & 79 & 0 \\
6 LEd & 339 & 538 & 77 & 46 \\
7 LUd & 814 & 80 & 93 & 13 \\
\hline
\end{tabular}

$1,55 \mathrm{~g} \mathrm{~cm}^{-3}$ (solo 5 - caulinítico). Esse valor muito mais el evado no L atossolo Amarel o se sobressaiu em relação aos demais, constituindo feição típica dessa classe coesa de solo (J acomine, 1996). Valores de densidade do solo mais baixos para Latossolos gibbsíticos e mais altos para Latossol os cauliníticos têm sido reportados na literatura (Silva et al ., 1995, 1998; Muggler et al., 1996; Chagas et al., 1997; Resende etal., 1999). A estabilidadedos agregados dos diferentes Latossolos, avaliada pelos métodos do peneiramento úmido e seco, está representada no quadro 4 pel os valores de diâmetromédiogeométrico(DMG). Verificase, a exemplo do que ocorreu com a Ds, que a estabilidade dos agregados também variou sobremaneira nos diferentes Latossol os, independentemente do método de avaliação, sendo digno de registro o valor muito mais baixo de DMG (água) no Latossolo Amarelo coeso, atributo distintivo dessa classe de Latossolo.

A porosidade total e a distribuição de poros por tamanho são apresentadas no quadro 5. Observa-se que os diferentes Latossolos revelaram grande variabilidade no que diz respeito à distribuiç̧ão de seus poros. Percebe-se que a porosidadetotal variou de 0,431 no solo 5 a $0,667 \mathrm{~m}^{3} \mathrm{~m}^{-3}$ no solo 3 . O Latossolo Amarelo coeso (solo 5), além de revelar menor porosi dadetotal, apresentou também o menor valor para a macroporosidade, em consonância com a sua gênese. Avaliando a distribuição de poros por tamanho, observou-se mai or variabilidade entre os Latossolos na classe dos macroporos, os quais, em última análise, determinam a taxa de movimentação da água no solo. Nesse conjunto de poros, o solo 6 (gibbsítico) destacou-se por apresentar a maior macroporosidade $\left(0,289 \mathrm{~m}^{3} \mathrm{~m}^{-3}\right)$, e o sol o 5, a menor macroporosidade $\left(0,131 \mathrm{~m}^{3} \mathrm{~m}^{-3}\right)$. Esses resultados corroboram aquel es obti dos por Chagas et al . (1997) eSilva \& Ribeiro (1997).

Os valores de condutividade hidráulica do solo saturado (Ks) dos diferentes sol os são apresentados

Quadro 4. Distribuição de partículas por tamanho, argila dispersa em água, índice de floculação, densi dade do solo e diâmetro médio geométrico dos agregados do horizonte Bw dos Latossolos estudados

\begin{tabular}{|c|c|c|c|c|c|c|c|c|c|}
\hline \multirow{2}{*}{ Solo } & \multicolumn{4}{|c|}{ Granulometria } & \multirow{2}{*}{$\begin{array}{l}\text { Argila dispersa } \\
\text { em água }\end{array}$} & \multirow{2}{*}{$\begin{array}{l}\text { Índice de } \\
\text { floculação }\end{array}$} & \multirow{2}{*}{$\begin{array}{l}\text { Densidade } \\
\text { do solo }\end{array}$} & \multicolumn{2}{|c|}{$\begin{array}{l}\text { Diâmetro médio } \\
\text { geométrico (DMG) }\end{array}$} \\
\hline & Areia grossa & Areia fina & Silte & Argila & & & & Água & Seco \\
\hline & 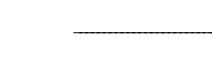 & - & $\mathrm{g} \mathrm{kg}^{-1}$ & & - & $\%$ & $\mathrm{~g} \mathrm{~cm}^{-3}$ & $-n$ & - \\
\hline $1 \mathrm{LEd}$ & 20 & 60 & 280 & 640 & 210 & 67 & 1,04 & 5,19 & 4,58 \\
\hline $2 \mathrm{LRd}$ & 50 & 50 & 360 & 540 & 150 & 72 & 1,06 & 4,78 & 2,49 \\
\hline $3 \mathrm{LEd}$ & 10 & 20 & 380 & 590 & 80 & 86 & 0,91 & 4,52 & 1,14 \\
\hline $4 \mathrm{LVd}$ & 160 & 170 & 160 & 510 & 140 & 72 & 1,09 & 4,49 & 2,11 \\
\hline $5 \mathrm{LAa}$ & 370 & 100 & 30 & 500 & 250 & 50 & 1,55 & 0,71 & 2,68 \\
\hline 6 LEd & 40 & 80 & 100 & 780 & 220 & 72 & 0,94 & 3,11 & 2,95 \\
\hline $7 \mathrm{LUd}$ & 210 & 80 & 80 & 630 & 0 & 100 & 1,14 & 2,38 & 3,80 \\
\hline
\end{tabular}


no quadro 6. Percebe-se, de imediato, uma elevada variabilidade da condutividade hidráulica dos diferentes solos, com relativamente grande estabi lidade dos sistemas frenteà passagem da água. O sol o 5 (caulinítico), consi derando sua alta Ds, baixa porosidade total e macroporosidade, além de alta coesão (observada no campo), apresentou o menor valor de Ks (1,4 cm h-1), feição característica dessa classe de Latossolo, sem muita ligação com seu teor de argila (Oliveira et al., 1992). Observa-se, ainda no quadro 6, que o solo 6, com $780 \mathrm{~g} \mathrm{~kg}^{-1}$ de argila, apresentou o maior valor de Ks $\left(61,9 \mathrm{~cm} \mathrm{~h}^{-1}\right)$. Esses resultados cor roboram as observações de Fernandes et al. (1978), Resende (1985) eSilva \& Ribeiro (1997). Deacordo com Fernandes et al. (1978), a condutividade hidráulica do solo acha-se mais bem relacionada com o volume de poros com diâmetro maior que $0,07 \mathrm{~mm}$. Segundo Resende (1985) e Resende et al. (1999), os Latossolos, mesmo quando muito argilosos, podem apresentar grande permeabilidade, em decorrência da estrutura granular muito pequena e muito bem expressa. Os aspectos relativos à estrutura dos diferentes Latossolos são discutidos em Ferreira et al. (1999).
Os coeficientes das análises de correlações envolvendo os resultados da caracterização física e os oriundos das caracterizações químicas e mineralógicas são apresentados no quadro 7. I nicial mente, percebem-se correlações significativas entre as propriedades físicas estudadas e os teores de $\mathrm{Al}_{2} \mathrm{O}_{3}$ do ataque sulfúrico, $\mathrm{Al}$ extraído pela solução de oxal ato de amônio $\left(\mathrm{Al}_{\mathrm{o}}\right)$, caulinita, gibbsita eteores de argila. Esses resultados demonstram a importância do Al no comportamento das propriedades físicas associadas à estrutura dos Latossolos e vão de encontro com os reportados por Saini et al. (1966) e Deshpande et al. (1968). Os resultados das correlações mostraram que os val ores de Ds variaram diretamente com os teores de caulinita e inversamente com os teores de gibbsita. A figura 1 ilustra a relação entre Ds e teores de caulinita dos Latossolos estudados. Esse comportamento da Ds foi determinado pelo desenvolvimento estrutural desses solos, conforme demonstrado por Ferreira et al. (1999). Os Latossol os cauliníticos, em razão do ajuste face a face das placas de caulinita, desenvol vem um plasma denso, quelhes confere valores mais el evados de Ds. Assim sendo,

Quadro 5. Distribuição de poros por tamanho no horizonte Bw dos diferentes Latossolos estudados

\begin{tabular}{|c|c|c|c|c|c|c|c|c|}
\hline \multirow{2}{*}{ Solo } & \multicolumn{5}{|c|}{ Diâmetro dos poros (mm) } & \multirow{2}{*}{ Total de poros } & \multirow{2}{*}{ Macroporos ${ }^{(1)}$} & \multirow{2}{*}{ Microporos } \\
\hline & $>0,15$ & $0,15-0,07$ & $0,07-0,05$ & $0,05-0,03$ & $<0,03$ & & & \\
\hline & & & & & $-m^{3} r$ & & & - \\
\hline 1 LE d & 0,082 & 0,085 & 0,059 & 0,042 & 0,348 & 0,616 & 0,226 & 0,390 \\
\hline $2 \mathrm{LRd}$ & 0,063 & 0,044 & 0,082 & 0,088 & 0,383 & 0,660 & 0,189 & 0,471 \\
\hline $3 \mathrm{LEd}$ & 0,063 & 0,081 & 0,089 & 0,071 & 0,363 & 0,667 & 0,233 & 0,434 \\
\hline $4 \mathrm{LVd}$ & 0,098 & 0,068 & 0,056 & 0,056 & 0,315 & 0,593 & 0,222 & 0,371 \\
\hline $5 \mathrm{LAa}$ & 0,059 & 0,055 & 0,017 & 0,021 & 0,279 & 0,431 & 0,131 & 0,300 \\
\hline $6 \mathrm{LEd}$ & 0,109 & 0,111 & 0,069 & 0,046 & 0,325 & 0,660 & 0,289 & 0,371 \\
\hline $7 \mathrm{LUd}$ & 0,074 & 0,067 & 0,031 & 0,026 & 0,387 & 0,585 & 0,172 & 0,413 \\
\hline
\end{tabular}

(1) Considerou-se 0,05 mm como limite do diâmetro para separação de macro e microporos.

Quadro 6. Condutividade hidráulica do solo saturado (Ks) no horizonte Bw dos diferentes Latossolos estudados

\begin{tabular}{|c|c|c|c|c|c|c|c|c|}
\hline \multirow{2}{*}{ Solo } & \multicolumn{8}{|c|}{ Condutividade hidráulica - Ks } \\
\hline & 1a hora & 2a hora & 3a hora & 4a hora & 5a hora & 6a hora & 7ạ hora & Média \\
\hline & \multicolumn{8}{|c|}{$\mathrm{cm} \mathrm{h}^{-1}$} \\
\hline $1 \mathrm{LEd}$ & 20,5 & 20,8 & 20,4 & 20,5 & 19,7 & 19,0 & 18,8 & 19,9 \\
\hline $2 \mathrm{LRd}$ & 23,6 & 23,9 & 24,5 & 24,5 & 24,1 & 23,6 & 24,3 & 24,1 \\
\hline 3 LEd & 24,8 & 24,5 & 24,5 & 24,4 & 23,6 & 23,2 & 23,1 & 24,0 \\
\hline $4 \mathrm{LVd}$ & 28,7 & 30,3 & 31,1 & 31,0 & 31,1 & 30,0 & 29,2 & 30,2 \\
\hline $5 \mathrm{LAa}$ & 1,9 & 1,7 & 1,6 & 1,4 & 1,2 & 1,1 & 1,0 & 1,4 \\
\hline $6 \mathrm{LEd}$ & 67,5 & 66,1 & 65,6 & 63,9 & 59,4 & 56,5 & 54,6 & 61,9 \\
\hline $7 \mathrm{LUd}$ & 8,9 & 8,8 & 8,0 & 7,6 & 7,2 & 7,1 & 7,1 & 7,8 \\
\hline
\end{tabular}


aos maiores teores de caulinita corresponderão Latossol os com os mai ores val ores de Ds. O contrário ocorrerá com os Latossolos gibbsíticos.

Com respeito aos resultados da estabilidade dos agregados (Quadro 7), observam-se dois comportamentos distintos. A análise efetuada pelo método do peneiramento seco não revel ou qual quer associação entreo DMG (seco) e os componentes das caracterizações químicas e mineralógicas. Entretanto, o método do peneiramento úmido revelou, inicialmente, um aspecto já discutido envolvendo a participação do Al. Notou-se correlação positiva significativa entre DMG (água) e teores de $\mathrm{Al}_{2} \mathrm{O}_{3}$ do ataque sulfúrico e do Al extraído pela solução de oxalato de amônio $\left(\mathrm{Al}_{\mathrm{o}}\right)$. Finalmente, observa-se que o DMG (água) correlacionou-se negativamente com os teores de caulinita e positivamente com os teores de gibbsita. A relação entre DMG (água) e os teores de caulinita éilustrada na figura 2. Os resultados aqui obtidos revelaram diferentes graus de estabilidade de agregados dentro do grupamento de Latossolos estudados, decrescendo esta estabilidade com o aumento do teor decaulinita. Assim, esses resultados podem ser considerados como a chave para o entendimento do comportamento antagônico da estabilidade dos agregados dos solos de clima tropical em relação aos sol os de clima temperado. É sabido que os solos de clima temperado apresentam menor estabilidade de agregados que os solos de clima tropical, notadamente os Latossolos. A razão desse comportamento está evidenciada pela maior proporção de argila silicatada naqueles solos em relação aos óxidos de $\mathrm{Fe}$ e de Al. Segundo os resultados do presente estudo, a maior estabilidade dos agregados desses $L$ atossol os foi devida aos óxidos deAl (gibbsita).

Quadro 7. Coeficientes das análises de correlações simples envolvendo os resultados das caracterizações físicas, químicas e mineralógicas do horizonte Bw dos Latossolos estudados

\begin{tabular}{|c|c|c|c|c|c|c|c|c|c|c|c|}
\hline & $\mathrm{Fe}_{2} \mathrm{O}_{3}$ & $\mathrm{Al}_{2} \mathrm{O}_{3}$ & $\mathbf{F e}_{\mathbf{d}}$ & $A I_{d}$ & $\mathbf{F e} \mathbf{e}_{\mathrm{o}}$ & $\mathbf{A l}_{\mathrm{o}}$ & Caulinita & Gibbsita & G oethita & Hematita & Argila \\
\hline Ds & $-0,49$ & $-0,84 * *$ & $-0,39$ & $-0,67$ & $-0,25$ & $-0,65$ & $0,74 *$ & $-0,70$ & $-0,05$ & $-0,34$ & $-0,56$ \\
\hline DMG (água) & 0,52 & $0,85^{* *}$ & 0,39 & 0,57 & 0,38 & $0,89 * *$ & $-0,92 * *$ & $0,89 * *$ & 0,39 & $-0,04$ & 0,07 \\
\hline DMG (seco) & $-0,04$ & 0,10 & 0,00 & 0,27 & $-0,23$ & $-0,43$ & 0,40 & 0,43 & $-0,57$ & $-0,26$ & 0,36 \\
\hline Macroporos & 0,13 & $0,79 *$ & 0,10 & 0,45 & $-0,05$ & 0,52 & $-0,59$ & 0,59 & 0,07 & 0,08 & $0,72 *$ \\
\hline $\mathrm{KS}$ & 0,13 & 0,53 & 0,11 & 0,21 & 0,08 & 0,41 & $-0,48$ & 0,49 & 0,22 & 0,20 & $0,69 *$ \\
\hline
\end{tabular}

*, ** significativos a 5 e $1 \%$, pelo teste t, respectivamente.

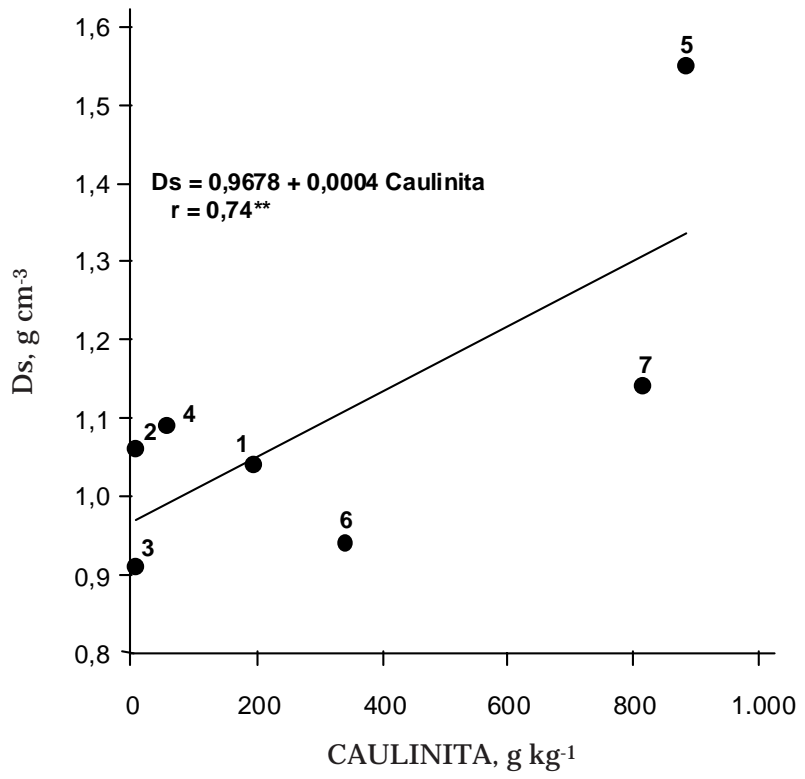

Figura 1. Relação entre densidade do solo (Ds) e teor de caulinita do horizonte $B w$ dos diferentes Latossolos estudados.

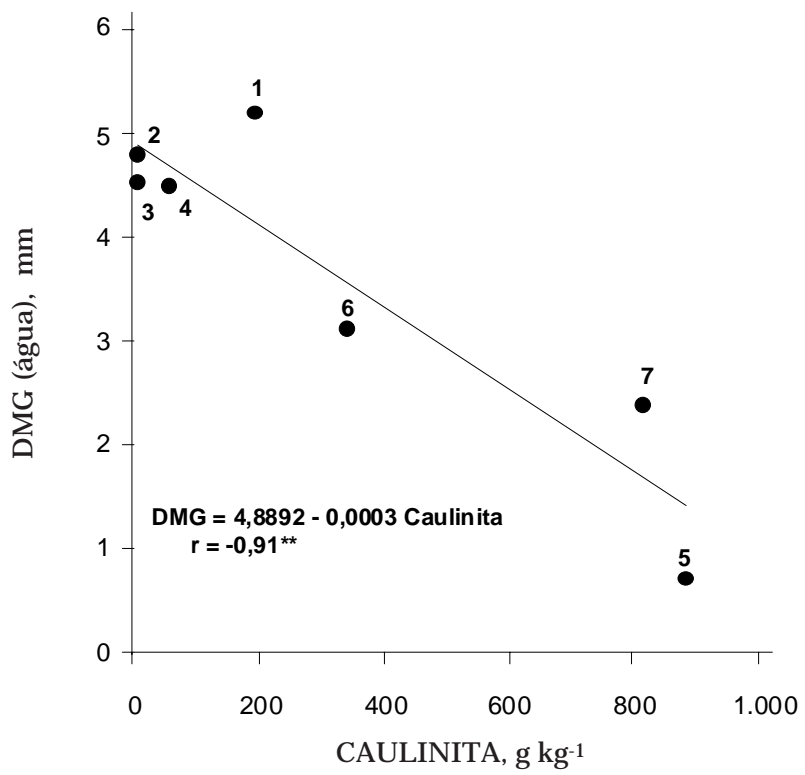

Figura 2. Relação entre diâmetro médio geométrico (DMG) dos agregados eteor decaulinita do horizonte Bw dos diferentes Latossolos estudados. 
Observa-se, ainda no quadro 7, que o teor de macroporos dos L atossol os correlacionou-se positiva e significativamente com o teor de $\mathrm{Al}_{2} \mathrm{O}_{3}$ do ataque sulfúrico e com o teor de argila, enquanto $\mathrm{Ks}$ correlacionou-se positiva e significativamente apenas com o teor de argila. Embora nãosignificativos, os coeficientes das correlações envolvendo os teores de caulinita e gibbsita foram relativamente elevados e apresentaram a mesma magnitude, todavia, com sinais opostos. Destacamse, no quadro 7, alguns aspectos interessantes. Inicialmente, percebe-se que, dos constituintes mineralógicos, caulinita e gibbsita foram os que melhor se associaram à macroporosidade e à condutividade hidráulica dos Latossolos estudados. Contudo, os relacionamentos foram antagônicos, ou seja, enquanto a presença da gi bbsita contribuiu para maior macroporosidade e maior condutividade hidráulica, a presença da caul inita atuou em sentido contrário (Figura 3). Tanto o teor de macroporos quanto o valor de Ks mostraram-se diretamente rel acionados com o conteúdo de argila dos $L$ atossol os.

Associando agora os resultados encontrados no presente estudo às afirmativas feitas por diversos autores, notadamente Resende et al. (1997), tornase razoável admitir que, quanto mais argiloso for 0 Latossolo, maior será sua permeabilidade(Figura 4). Deve-seressaltar, entretanto, queo LatossoloAmarelo em razão da sua coesão e da grande variabilidade de seu material de origem (sedimentos do Grupo Barreiras) poderá constituir exceção a essa admissão, suscitando futuros estudos que analisem maior número de exemplares dessa classe de solo.

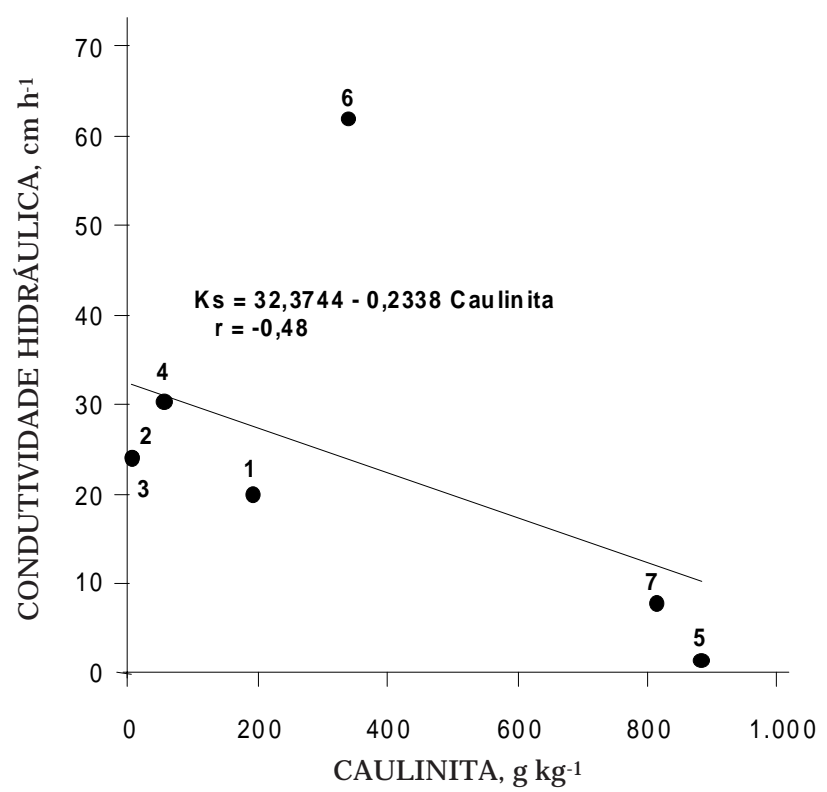

Figura 3. Relação entre condutividade hidráulica (Ks) do solo e teor de caulinita do horizonte Bw dos diferentes Latossolos estudados.

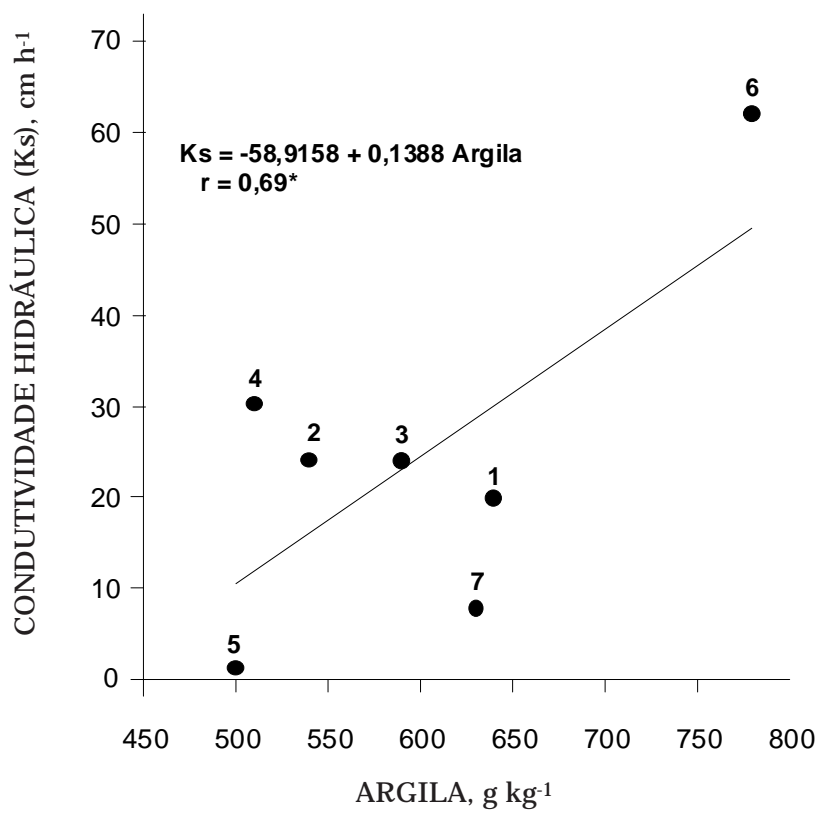

Figura 4. Relação entre condutividade hidráulica (Ks) do solo e teor de argila do horizonte Bw dos diferentes Latossolos estudados.

\section{CONCLUSÕES}

1. A influência do Al sobreas propriedades físicas associadas à estrutura dos L atossol os estudados foi mais pronunciada que a do $\mathrm{Fe}$.

2. Caulinita e gibbsita foram os constituintes mineralógi cos que maior influência exerceram sobre as propriedades físicas estudadas dos Latossol os da região Sudeste do Brasil.

3. Latossolos cauliníticos apresentaram maior densidade do solo, menor estabilidade de agregados em água, menor macroporosidade e menor permeabilidade, quando comparados a Latossolos gibbsíticos.

4. A permeabilidade dos Latossolos estudados aumentou com o teor de argila.

\section{LITE RATURA CITADA}

BOUMA, J . Guide to the study of water movement in soil pedons above the watertable. Madison, University of Wisconsin, 1973. 194p.

CHAGAS, C.S.; CURI, N.; DUARTE, M.N.; MOTTA, P.E.F. \& LIMA, J .M. Orientação das camadas de rochas metapelíticas pobres na gênese de Latossol os sob cerrado. Pesq. Agropec. Bras., 32:539-548, 1997.

CURI, N. \& FRANZMEIER, D.P. Toposequence of Oxisols from the Central Plateau of Brazil. Soil Sci. Soc. Am. J ., 48:341346, 1984. 
DAY, P.R. Particle fractionation and particle-size analysis. In: BLACK, C.A., ed. Methods of soil analysis. Physical and mineralogical properties including statistics of measurement and sampling. Part 1. Madison, American Society of Agronomy, 1965. p.545-567.

DESHPANDE, T.L.; GREENLAND, D.J . \& QUIRK,J .P. Changes in soil properties associated with the removal of iron and aluminium oxides. J . Soil Sci., 19:108-122, 1968.

DICK, D.P. \& KÄMPF, N. Comparação da extração de ferro com $\mathrm{HCl} 6 \mathrm{~N}, \mathrm{H}_{2} \mathrm{SO}_{4}$ 1:1 e ditionito-citrato-bicarbonato de sódio em horizontes B-latossólicos. R. Bras. Ci. Solo, 12:185-188, 1988.

EMPRESA BRASILEIRA DE PESQUISA AGROPECUÁRIA EMBRAPA. Serviço Nacional de Levantamento e Conservação de Solos. Levantamento de reconhecimento dos solos do estado do Espírito Santo. Rio deJ aneiro, 1978. 461p. (Boletim Técnico, 45)

EMPRESA BRASILEIRA DE PESQUISA AGROPECUÁRIA EMBRAPA. Serviço Nacional de Levantamento e Conservação de Solos. Manual de métodos de análise de solo. Rio de J aneiro, 1979. não paginado.

EMPRESA BRASILEIRA DE PESQUISA AGROPECUÁRIA EMBRAPA. Serviço Nacional de Levantamento e Conservação de Solos. Estudo expedito de solos da região do Alto Paranaíba, para fins de classificação, correlação e legenda preliminar. Rio de J aneiro, 1980. 84p. (Boletim Técnico, 64)

FERNANDES, B.; RESENDE, M. \& REZENDE, S.B. Caracterização deal guns sol os sob cerrado e disponibilidade de água para as culturas. Experientiae, 24:209-260, 1978.

FERNANDES, B.; GALLOWAY, H.M.; BRONSON, R.D. \& MANNERING, J.V. Condutividade hidráulica do solo saturado, em três sistemas de manejo. R. Ceres, 30:232241, 1983.

FERREIRA, M.M. Influência da mineral ogia da fração argila nas propriedades físicas de Latossolos brasileiros. Viçosa, Universidade Federal de Viçosa, 1988. 79p. (Tese de Doutorado)

FERREIRA, M.M.; FERNANDES, B. \& CURI, N. Mineralogia da fração argila e estrutura de $L$ atossol os da região Sudeste do Brasil. R. Bras. Ci. Solo, 23:507-514, 1999.

HARRIS, R.F.; CHESTER, G. \& ALLEN, O.N. Dynamics of soil aggregation. Adv. Agron., 18:107-169, 1966.

J ACOMINE, P.K.T. Distribuição geográfica, características e classificação dos solos coesos dos tabuleiros costeiros. In: REUNIÃO TÉCNICA SOBRE SOLOS COESOS DOS TABULEIROS COSTEIROS, Cruz das AImas, 1996. Anais. Aracaju, EMBRAPA-CPATC/EMBRAPA-CNPMF/ EAUFBA/IGUFBA, 1996. p.13-26.

KÄMPF, N. \& SCHWERTMANN, U. The $5 \mathrm{M} \mathrm{NaOH}$ concentration treatment for iron oxides in soils. Clays Clay Miner., 30:401408, 1982.

LIMA, J .M. \& ANDERSON, S.J . Aggregation and aggregate size effects on extractableiron and aluminum in two Hapludoxs. Soil Sci. Soc. Am. J ., 61:965-970, 1997.
MARCOS, Z.Z. Estrutura, agregação e água do solo. Piracicaba, Escola Superior de Agricultura Luiz de Queiróz, 1968. 55p. (Tese de Doutorado)

MAZURACK, A.P. Effect of gaseous phase on water-stable synthetic aggregates. Soil Sci., 69:135-148, 1950.

McINTYRE, D.S. The effect of free ferric oxide on the structure of some terra rossa and rendzina soils. J. Soil Sci., 7:302306, 1956.

MEHRA, O.P. \& J ACKSON, M.L. I ron oxide removal from soils and clays by dithionite-citrate-bicarbonate system buffered with sodium bicarbonate. Clays Clay Miner., 7:317-327, 1960.

MIELKE, L.E. Encansing undisturbed soil cores in plastic. Proc. Soil Sci. Soc. Am., 37:325-326, 1973.

MUGGLER, C.C.; CURI, N.; SILVA, M.L.N. \& LIMA, J.M. Características pedológicas de ambientes agrícolas nos chapadões do Rio Corrente, sudoeste da Bahia. Pesq. Agropec. Bras., 31:221-232, 1996.

MUGGLER, C.C. Polygenetic Oxisols on tertiary surfaces, Minas Gerais, Brazil: soil genesis and landscape development. Wageningen, Wageningen Agricultural University, 1998. 186p. (Tese de Doutorado)

NORRISH, K. \& TAYLOR, R.M. The isomorphous replacement of iron by aluminium in soil goethites. J. Soil Sci., 12:294306, 1961.

OLIVEIRA, J .B.; J ACOMINE, P.K.T. \& CAMARGO, M.N. Classes gerais de solos do Brasil: guia auxiliar para seu reconhecimento. J aboticabal, FUNEP, 1992. 201p.

PINHEIRO-DICK, D. \& SCHWERTMANN, U. Microaggregates from Oxisols and Inceptisols: dispersion through selective dissolutions and physicochemical treatments. Geoderma, 74:49-63, 1996.

RESENDE, M. Mineralogy, chemistry, morphology and geomorphology of some soils of the Central Plateau of Brazil. West Lafayette, PurdueUniversity, 1976. 237p. (Tese de Doutorado)

RESENDE, M. Aplicações de conhecimentos pedológicos à conservação de sol os. Inf. Agropec., 128:3-18, 1985.

RESENDE, M.; BAHIA FILHO, A.F.C. \& BRAGA, J.M. Mineralogia da argila de Latossolos estimada por alocação a partir do teor de óxidos do ataque sulfúrico. R. Bras. Ci. Solo, 11:17-23, 1987.

RESENDE, M. \& SANTANA, D.P. Uso das relações Ki e Kr na estimativa da mineral ogia para classificação de Latossol os. In: REUNIÃO DE CLASSIFICAÇÃO, CORRELAÇÃO DE SOLOS E INTERPRETAÇÃO DA APTIDÃO AGRÍCOLA, 3., Rio deJ aneiro, 1988. Anais. Rio deJ aneiro, EMBRAPASNLCS/SBCS, 1988. p.225-232.

RESENDE, M.; CURI, N.; REZENDE, S.B. \& CORRÊA, G.F. Pedologia: base para distinção de ambientes. 2.ed. Viçosa, NEPUT, 1997. 367p.

RESENDE, M.; CURI, N. \& LANI, J .L. Tropical soils: implications on sustainable development. In: SCIENCE for Sustainable Development in Latin America and Caribbean. Rio de J aneiro: Academia Brasileira de Ciências, 1999. não paginado. 
SAINI, G.R.; Mac LEAN, A.A. \& DOYLE, J J . The influence of some physical and chemical properties on soil aggregation and response to VAMA. Can. J. Soil Sci., 46:155-160, 1966.

SCHWERTMANN, U. Differenzierung der eisenoxyde des bodens durch extraktation mit ammoniumoxalat-Losung. Z. Pflanzenernahr. Bodenkd., 105:195-202, 1964.

SCHWERTMANN, U. \& KÄMPF, N. Properties of goethite and hematite in kaolinitic soils of southern and Central Brazil. Soil Sci., 139:344-350, 1985.

SILVA, A.J .N. \& RIBEIRO, M.R. Caracterização de Latossolo Amarelo sob cultivo contínuo de cana-de-açúcar no estado deAlagoas: atributos morfológicos efísicos. R. Bras. Ci. Solo, 21:677-684, 1997.
SILVA, M.L.N.; CURI, N.; MARQUES, J JJ .G.S.M.; LIMA, L.A.; FERREIRA, M.M. \& LIMA, J.M. Resistência ao salpico provocado por impacto de gotas de chuva simulada em Latossolos e sua relação com características químicas e mineralógicas. Ci. Prat., 19:176-182, 1995

SILVA, M.L.N.; BLANCANEAUX, P.; CURI, N.; LIMA, J .M.; MARQUES, J J .G.S.M. \& CARVALHO, A.M. Estabilidadee resistência de agregados de Latossolo Vermel ho-Escuro cultivado com sucessão milho-adubo verde. Pesq. Agropec. Bras., 33:97-103, 1998.

VETTORI, L. Métodos de análises de solo. Rio de J aneiro, Ministério da Agricultura, Equipe dePedologia eFertilidade do Solo, 1969. 24p. (Boletim Técnico, 7)

YODER, R.E. A direct method of aggregate analysis of soils and study of the physical nature of erosion losses. J. Am. Soc. Agron., 28:337-351, 1936. 